\title{
Acute nicotine enhances spontaneous recovery of contextual fear and changes $c$-fos early gene expression in infralimbic cortex, hippocampus, and amygdala
}

\author{
Munir G. Kutlu, Jessica M. Tumolo, Erica Holliday, Brendan Garrett, and Thomas J. Gould \\ Department of Psychology, Neuroscience Program, Weiss Hall, Temple University, Philadelphia, Pennsylvania 19122, USA
}

\begin{abstract}
Exposure therapy, which focuses on extinguishing fear-triggering cues and contexts, is widely used to treat post-traumatic stress disorder (PTSD). Yet, PTSD patients who received successful exposure therapy are vulnerable to relapse of fear response after a period of time, a phenomenon known as spontaneous recovery (SR). Increasing evidence suggests ventral hippocampus, basolateral amygdala, and infralimbic cortex may be involved in SR. PTSD patients also show high rates of comorbidity with nicotine dependence. While the comorbidity between smoking and PTSD might suggest nicotine may alter SR, the effects of nicotine on SR of contextual fear are unknown. In the present study, we tested the effects of acute nicotine administration on SR of extinguished contextual fear memories and c-fos immediate early gene immunohistochemistry in mice. Our results demonstrated that acute nicotine enhanced SR of extinguished fear whereas acute nicotine did not affect retrieval of unextinguished contextual memories. This suggests that the effect of acute nicotine on SR is specific for memories that have undergone extinction treatment. $C$-fos immunoreactive (IR) cells in the ventral hippocampus and basolateral amygdala were increased in the nicotine-treated mice following testing for SR, whereas the number of IR cells in the infralimbic cortex was decreased in the same group. Overall, this study suggests that nicotine may adversely affect context-specific relapse of fear memories and this effect is potentially mediated by the suppression of cortical regions and increased activity in the ventral hippocampus and amygdala.
\end{abstract}

[Supplemental material is available for this article.]

Lifetime prevalence of exposure to traumatic events is around 90\% (Breslau et al. 1998). After a traumatic event, negative emotional responses usually extinguish unless the traumatic event reoccurs. In individuals with post-traumatic stress disorder (PTSD), however, the extinction process fails and the emotional response becomes persistent (Rothbaum and Davis 2003) leading to symptoms including exaggerated fear response to cues and contexts that are not dangerous (Gualtieri and Morgan 2008). Exposure therapy, which is widely used to treat PTSD (Chambless and Ollendick 2001), focuses on extinguishing fear-triggering cues and contexts. Although exposure-based therapies alleviate PTSD symptoms in $60 \%-80 \%$ of patients, recovery of fear responses (i.e., relapse) often occurs. Relapse in PTSD and other anxiety disorders is common; depending on the type of anxiety disorder, an estimated $19 \%-62 \%$ of patients experience relapse after completion of exposure therapy (Vervliet et al. 2013). This is because during extinction, fear memories are not erased but are actively suppressed by a secondary inhibitory memory (Myers and Davis 2002). One source of fear relapse is known as spontaneous recovery (SR) (Pavlov 1927; Myers and Davis 2002), in which an extinguished stimulus spontaneously triggers a fear response after completion of therapy (Craske and Rachman 1987). Although several theoretical accounts offer potential explanations for SR (e.g., Bouton 1988; Kutlu and Schmajuk 2012), little is known about the processes leading to fear relapse.

Importantly, PTSD patients show high-comorbidity with nicotine dependence (Breslau et al. 2004). Smoking rates among PTSD patients (45.3\%) are significantly higher than the nonclinical population (22.5\%, Ziedonis et al. 2008). In addition, a sig-

Corresponding author: munir.kutlu@temple.edu

Article is online at http://www.learnmem.org/cgi/doi/10.1101//m.042655.116. nificant positive correlation exists between smoking and PTSD symptoms and the severity of PTSD symptoms is predicted by daily number of cigarettes smoked (Thorndike et al. 2006; Greenberg et al. 2012). Beyond PTSD, smoking rates increase when healthy individuals encounter stressful/anxiogenic situations (Pomerleau and Pomerleau 1987). Importantly, Breslau et al. (2003) showed that PTSD patients had significantly higher rates of smoking initiation following trauma compared with individuals not exposed to trauma ( $31.7 \%$ versus $10.4 \%)$. In addition, there is evidence showing that acute nicotine intake increases the likelihood of intrusive traumatic memories in healthy nonsmokers (Hawkins and Cougle 2013). Moreover, evidence from multiple animal studies showed that acute nicotine enhances contextual fear learning (Gould and Higgins 2003; Gould and Lommock 2003; Davis et al. 2006) and disrupts extinction of fear memories (Kutlu and Gould 2014; Kutlu et al. 2016; for review, see Kutlu and Gould 2015). Therefore, given the higher rates of smoking initiation in PTSD patients, the period of acute nicotine intake following a traumatic event may be especially critical for the development and relapse of fear in PTSD. However, the effects of acute nicotine on fear relapse and the brain regions involved are unknown. Several brain regions, such as the hippocampus, amygdala, and prefrontal cortex, have been implicated in processes that support the acquisition and recall of extinction memories (Falls et al. 1992; Milad and Quirk 2002; Quirk and

(C) 2016 Kutlu et al. This article is distributed exclusively by Cold Spring Harbor Laboratory Press for the first 12 months after the full-issue publication date (see http://learnmem.cshlp.org/site/misc/terms.xhtml). After 12 months, it is available under a Creative Commons License (AttributionNonCommercial 4.0 International), as described at http://creativecommons. org/licenses/by-nc/4.0/. 
Mueller 2008; Sierra-Mercado et al. 2011). Specifically, increased activation in prefrontal cortex may support extinction while increased activity in the hippocampus and amygdala may support fear expression (Sierra-Mercado et al. 2011). The effects of acute nicotine on these brain regions during SR, however, are not known. Therefore, this study tested the hypothesis that nicotine would increase SR and c-fos activity in the hippocampus and amygdala while decreasing prefrontal activity.

\section{Materials and Methods}

\section{Subjects}

Naïve adult (8-wk old) male C57BL/6J mice (Jackson Laboratory, Bar Harbor, ME) were group-housed in a colony room maintained on a $12 \mathrm{~h}$ light-dark with ad libitum water and food. Procedures used in this study were approved by the Temple University Institutional Animal Care and Use Committee.

\section{Apparatus}

Behavioral experiments took place in four identical chambers $(18.8 \times 20 \times 18.3 \mathrm{~cm})$ placed in sound attenuating boxes (MED Associates). Ventilation fans mounted in the chambers produced a background noise $(65 \mathrm{~dB})$ and the 30 -sec white noise $(85 \mathrm{~dB})$ conditioned stimulus (CS). The chambers were composed of Plexiglas and the chamber floors were metal grids $(0.20 \mathrm{~cm}$ in diameter and $1.0 \mathrm{~cm}$ apart) connected to a shock generator, which delivered a 2 -sec, 0.57 -mA foot shock unconditioned stimulus (US).

\section{Drug administration}

Nicotine hydrogen tartrate salt $(0.18 \mathrm{mg} / \mathrm{kg}$ freebase, Sigma) dissolved in saline or saline alone were administered intraperitoneally (i.p.) 2-4 min prior to behavioral testing. This dose and the injection time were based on previous studies (Kutlu and Gould 2014). Also, this dose produced plasma nicotine levels comparable with human smokers Davis et al. 2005). Injection volumes were $10 \mathrm{~mL} / \mathrm{kg}$ as in previous studies (e.g., Kutlu and Gould 2014).

\section{Behavioral procedures}

Freezing, defined as the absence of voluntary movement except respiration (Davis et al. 2005), to the context was the dependent variable. Subjects were observed every $10 \mathrm{sec}$ for a duration of $1 \mathrm{sec}$ and scored as active or freezing (Blanchard and Blanchard 1972). Following the background contextual fear conditioning procedure used in our previous studies (Kutlu and Gould 2014; Kutlu et al. 2016), in Experiment 1, mice received contextual fear conditioning training, in which they were first placed in the conditioning chambers and baseline freezing was assessed for $120 \mathrm{sec}$, and then the mice received two white noise-foot shock pairings where the offset of the white noise coincided with the offset of the 2-sec foot shock. (see Fig. 1 for the schematic experimental designs). Two CS-US trials were separated by a 120-sec intertrial interval. All mice remained in the chamber for another $30 \mathrm{sec}$ after the second white noise-foot shock paring. The next day all mice were placed back in the conditioning chamber for 5 min to score initial freezing to the context in the absence of the foot shock. Then mice were given single daily contextual extinction sessions for $5 \mathrm{~d}$ where they were placed back in the conditioning context for $5 \mathrm{~min}$ in order to extinguish contextual freezing. Seven days after the last extinction session mice were returned to the conditioning context to test for SR. Animals were administered acute nicotine $(0.18 \mathrm{mg} / \mathrm{kg})$ or saline i.p. $2-4$ min prior to the SR session. In Experiment 2, we determined if nicotine affects recall of contextual fear memories in general. Mice were fear conditioned and $24 \mathrm{~h}$ later tested for initial freezing. Mice did not undergo extinction treatment; instead they remained in their homecages for a total of $12 \mathrm{~d}$ before they were retested for fear recall. A second group of mice in Experiment 2 received the same drug treatment but were given 1 CS-US pairing instead of 2 CS-US pairings during training in order to rule out the possibility that acute nicotine only enhances lower levels of freezing. Mice received i.p. injections of nicotine $(0.18 \mathrm{mg} / \mathrm{kg})$ or saline 2-4 min before retesting.

\section{c-fos immunohistochemistry}

The effects of nicotine on $c$-fos expression in the hippocampus, amygdala, and prefrontal cortex (PFC) during SR and memory

\section{Experiment 1}

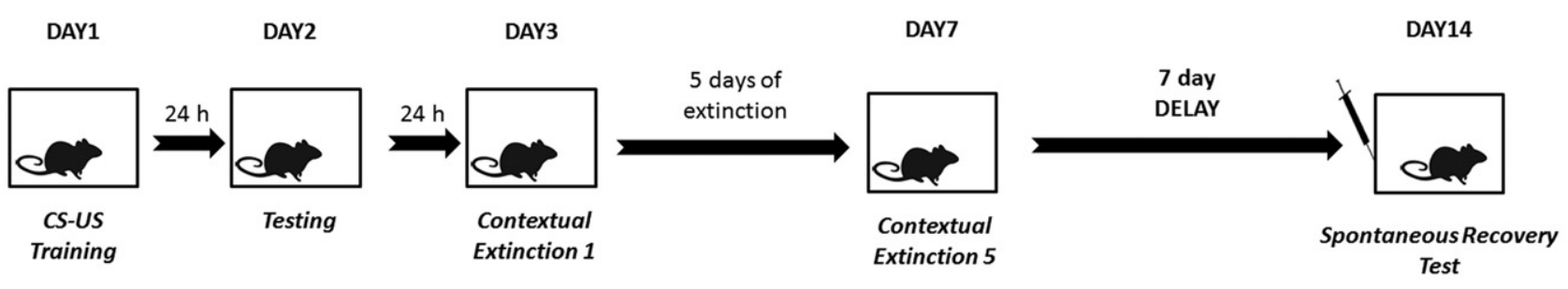

\section{Experiment 2}

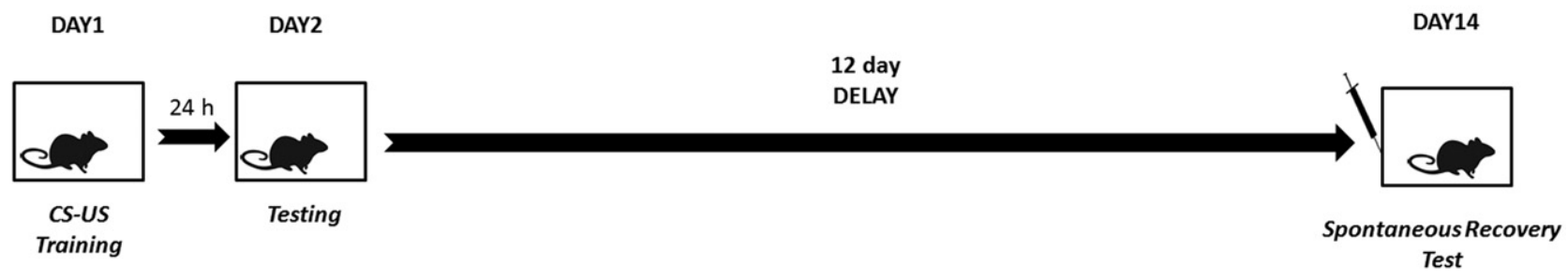

Figure 1. The schematic designs of Experiment 1 and 2. Each box represents a phase of the experiment and the syringes represent nicotine or saline injections. 
recall were examined in another cohort of C57BL/6J mice that underwent the same behavioral and drug treatment as Experiment 1. In addition to the nicotine and saline groups that received training, extinction and retesting (Nic/Extinction and Sal/Extinction), two groups of mice received only training and retesting following nicotine $(0.18 \mathrm{mg} / \mathrm{kg})$ or saline injections to control the effects of extinction (Nic/NoExtinction and Sal/NoExtinction). Another two groups of mice received the same drug treatments but stayed in their homecages (Nic/ Homecage and Sal/Homecage) to control for the nonspecific effects of nicotine and i.p. injections. Mice were perfused $1 \mathrm{~h}$ after retesting using phosphate buffered saline (PBS, $0.1 \mathrm{M}$ ) followed by $4 \%$ paraformaldehyde (PFA, $\mathrm{pH}$ 7.4) in PBS and brains were collected and stored in PFA. Twenty-four hours later, brains were switched to $30 \%$ sucrose, and coronal sections were collected 2 d later. The $c$-fos immunohistochemistry was performed using floating sections washed in PBS $(3 \times 5 \mathrm{~min})$ and in $0.75 \%$ hydrogen peroxide for $20 \mathrm{~min}$ to quench endogenous peroxidase activity. Then the sections were washed using PBS with Triton-X and Bovine Serum Albumin (PBS-TX-BSA) solution and incubated in a rabbit-host polyclonal antibody (c-fos, 1:1000 in PBS-TX-BSA with Sodium Azide; Santa Cruz Biotechnology) for two nights at room temperature. Following PBS-TX-BSA washes $(3 \times 10 \mathrm{~min})$, the sections were incubated in the secondary antibody (biotinylated goat-anti rabbit, 1:200 in PBS-TX-BSA; Jackson ImmunoResearch) for $90 \mathrm{~min}$, washed again in PBS-TX-BSA $(3 \times 10 \mathrm{~min})$ and incubated in avidin-biotin complex (1:600 in PBS; Vector $\mathrm{ABC}$ kit) for $30 \mathrm{~min}$ at room temperature. An oxidase-diaminobenzidine-nickel (DAB) method was used for the immunostaining reaction (5 min, diaminobenzidine, DAB Nickel Substrate Kit, Vector Laboratories) and the reaction was stopped using a 5 min $\mathrm{dH}_{2} \mathrm{O}$ wash. The sections were then rinsed in phosphate buffer $(2 \times 10 \mathrm{~min})$ and mounted on slides. Slides were air-dried for $24 \mathrm{~h}$ before dehydration using ethanol and xylene washes and cover slipped using Permount (Fisher Chemicals).

The dorsal hippocampus (dHipp; CA1, CA3, and dentate gyrus), ventral hippocampus (vHipp; CA1, CA3, and dentate gyrus), medial prefrontal cortex (paralimbic [PL] and infralimbic [IL] cortices), and basolateral nucleus of the amygdala (BLA) were selected as the regions of interest (ROI) based on their significant roles in extinction of fear conditioning (Falls et al. 1992; Milad and Quirk 2002; Quirk and Mueller 2008; Sierra-Mercado et al. 2011); (coordinates for ROIs were based on Paxinos and Franklin (2001), dHipp, -1.58 to $-2.54 \mathrm{~mm}$ posterior to bregma; vHipp, -2.70 to $-3.64 \mathrm{~mm}$ posterior to bregma; PL, 1.54 to $1.98 \mathrm{~mm}$ anterior to bregma; IL, 1.54 to $1.98 \mathrm{~mm}$ anterior to bregma; and BLA, -0.82 to $-1.70 \mathrm{~mm}$ posterior to bregma). Sections were visualized under a brightfield microscope (Leica), $20 \times$ images were taken for each brain region. Using the ImageJ $(1.48 \mathrm{v})$ software, we subtracted the background and thresholded the images in order to separate $c$-fos signal from background and reduce noise. A custom ImageJ macro was used to count the $c$-fos immunoreactive neurons based on pixel intensity. Only c-fos signals that were above threshold were counted as c-fos-positive cells following previous studies (e.g., Zhao and Li 2010). Three measurements from the given anterior-posterior coordinates for each brain region (every fourth section for IL and PL and every eighth section for dHipp, vHipp, and BLA) were averaged (Martinez et al. 2013) and expressed as the number of $c$-fos-positive cells per millimeter square $\left(\mathrm{mm}^{2}\right)$.

\section{Statistical analysis}

For the behavioral experiments, we converted freezing behavior to percent freezing. Spontaneous recovery was expressed as percent rebound to the freezing levels measured during initial testing (\%Rebound; average freezing during retesting $\times 100$ /average freezing during initial testing; Santini et al. 2001). Following studies examining recovery of conditioned behavior such as freezing, fear potentiated-startle, and drug self-administration (e.g., Morgan et al. 1993; Corcoran et al. 2005; Norrholm et al. 2006; Baratta et al. 2007; Wing and Shoaib 2008), an extinction criterion was employed to ensure successful extinction learning. Specifically, animals that did not show freezing levels below $30 \%$ of their initial freezing levels at the end of the extinction phase were removed from analysis as freezing levels above this level may indicate incomplete extinction. The extinction criterion resulted in the removal of two animals from each drug group in Experiment 1 . To examine the main effect of Drug (nicotine versus saline), we used two separate one-way ANOVAs at $\alpha=0.05$. For $c$-fos immunohistochemistry, the number of $c$-fos IR cells was converted to number of cells per $\mathrm{mm}^{2}$ (number of $c$-fos IR cells per area of the count; $0.31952 \mathrm{~mm}^{2}$ ). A multivariate ANOVA was run for all ROIs together to detect Drug (nicotine versus saline) $\times$ Training (extinction versus homecage versus no extinction) interaction, which were followed by Tukey post hoc tests to examine group differences. Group sizes are indicated in figure captions.

\section{Results}

Experiment 1: acute nicotine enhances SR of contextual fear In Experiment 1, we examined the effects of acute nicotine administered prior to testing on SR of contextual fear. A repeatedmeasure ANOVA showed no between group differences in freezing during extinction $\left(F_{(5,65)}=0.818, P>0.05\right)$. One-way ANOVAs yielded a significant main effect of Drug for both \%freezing during retesting $\left(F_{(1,13)}=5.805, P<0.05\right)$ and \%Rebound $\left(F_{(1,13)}=\right.$ 9.769, $P<0.05)$. This suggests that while saline treated mice showed normal SR of contextual fear $(\sim 80 \%$ rebound), acute nicotine significantly enhanced SR (183\% rebound, Fig. 2; see Supplemental Fig. S1 for within-session freezing levels).

\section{Experiment 2: acute nicotine does not affect retrieval of unextinguished contextual fear memories}

The results of Experiment 1 show increased contextual fear expression during retesting in mice that received acute nicotine prior to retesting, suggesting enhanced SR of contextual fear. However, this result could also indicate that either acute nicotine enhances retrieval of contextual fear memories in general or decreases locomotor activity. To address this issue, we administered acute nicotine prior to retesting but this time mice did not undergo extinction. A one-way ANOVA showed no group differences in freezing during initial testing $\left(F_{(1,13)}=0.005, P>0.05\right)$. One-way ANOVAs showed no main effect of Drug on retesting \%freezing $\left(F_{(1,13)}=0.016, P>0.05\right)$ or \%Recall $\left(F_{(1,13)}=0.004, P>0.05\right)$. This suggests that the effects of acute nicotine administered prior to retesting are specific to SR of extinguished contextual fear as both saline and nicotine treated groups showed similar levels of $\%$ Recall during retesting ( $\sim 100 \%$, Fig. 3A). Similar results were achieved when initial freezing levels were reduced by employing 1 CS-US pairing during training (Fig. 3B). A one-way ANOVA showed no group differences in freezing during initial testing $\left(F_{(1,16)}=0.005, P>0.05\right)$, no main effect of Drug on retesting \%freezing $\left(F_{(1,16)}=0.036, P>0.05\right)$ or \%Recall $\left(F_{(1,16)}=0.151\right.$, $P>0.05)$. This suggests that acute nicotine's enhancing effects on spontaneous recovery is not due to the lower levels of freezing at the end of extinction but rather depends on possible differential retrieval mechanisms of intact and extinguished fear.

\section{Experiment 3: acute nicotine-induced enhancement of SR of contextual fear increases activity in vHipp and BLA while decreasing IL activity}

Experiment 3 identified $c$-fos expression changes in brain regions potentially involved in the effects of acute nicotine on SR of contextual fear. Representative coronal sections included in this analysis are shown in Figure 4. A multivariate ANOVA was used to calculate all main effects and interactions across all ROIs. Within the hippocampus, the Drug (nicotine versus saline) $\times$ Training (extinction versus homecage versus no extinction) 


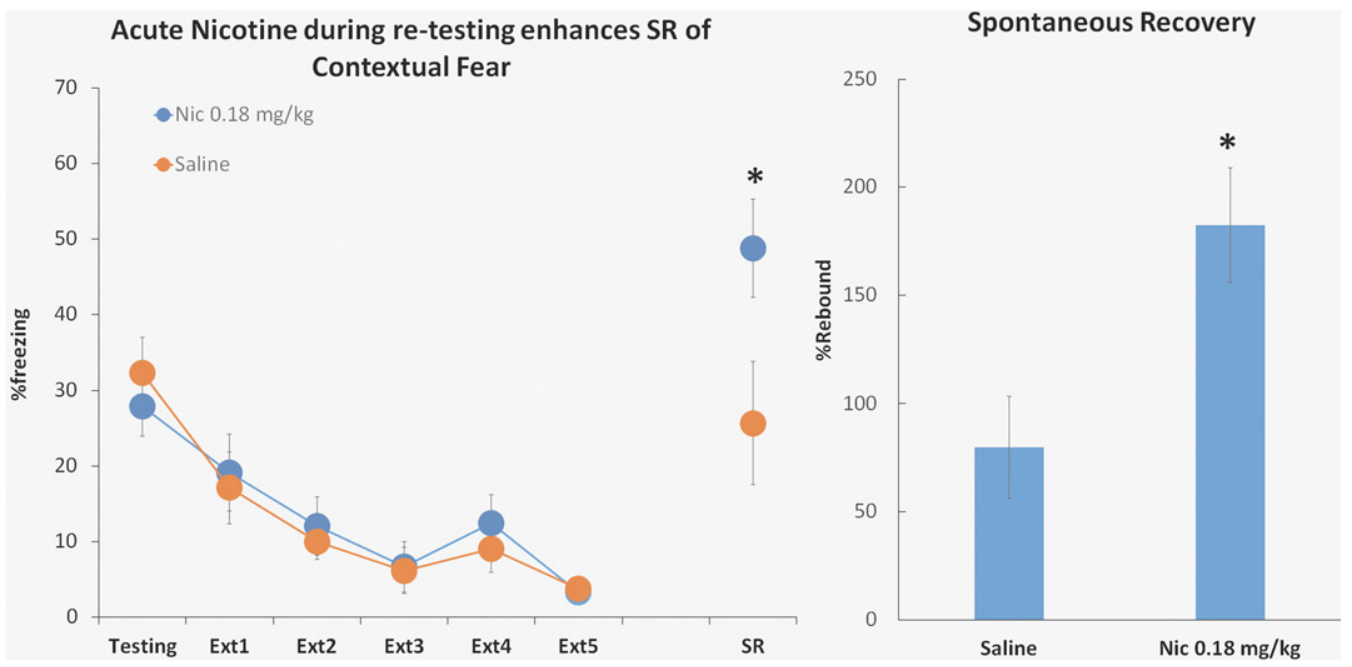

Figure 2. Acute nicotine enhances SR of contextual fear. (Left panel) Acute-nicotine $(0.18 \mathrm{mg} / \mathrm{kg}$ ) administration prior to retesting enhanced SR of contextual fear represented as \%freezing in mice ( $n=7-8$ per group). (Right panel) Spontaneous recovery of contextual fear represented as \%Rebound (average freezing during retesting $\times 100$ /average freezing during initial testing) in the nicotine and saline groups. Error bars indicate standard error of the mean (SEM) and asterisks represent differences from the saline group at the $P<0.05$ level.

interaction was significant for vHipp $\left(F_{(5,34)}=15.559, P<0.01\right)$ but not dHipp $\left(F_{(5,34)}=0.502, P>0.05\right)$ when CA1, CA3, and DG c-fos IR cell numbers are averaged for each ROI. Similarly, the Drug $\times$ Training interaction was significant for the CA1 $\left(F_{(5,34)}=12.833, P<0.01\right)$, CA3 $\left(F_{(5,34)}=11.234, P<0.01\right)$ and DG $\left(F_{(5,34)}=5.330, P<0.05\right)$ subregions of vHipp but not significant for the same subregions of dHipp (CA1, $F_{(5,34)}=0.189$, $P>0.05 ;$ CA3, $F_{(5,34)}=0.921, P>0.05 ;$ DG, $F_{(5,34)}=0.540$, $P>0.05)$. Tukey post hoc tests also revealed that the number of $c$-fos IR cells in the Nic/Extinction group was significantly different than the Sal/Extinction, Nic/Homecage, and Sal/Homecage groups in vHipp as well as in all three subregions of vHipp (Ps < 0.05). Furthermore, the Nic/NoExtinction group $c$-fos IR cell numbers were significantly different from the homecage controls and the Nic/Extinction group $(P s<0.05)$ but not from the Sal/ NoExtinction group in vHipp. However, no between-group differences were detected for dHipp. In sum, these results indicate a clear dissociation between dorsal and ventral hippocampus in the effects of acute nicotine on SR of contextual fear. While vHipp c-fos expression was increased during the acute nicotineinduced enhancement of SR, it remained unchanged when nicotine was administered alone in the absence of training (Fig. 5A). Moreover, our results suggest that vHipp $c$-fos expression did not differ between the saline and nicotine-treated groups that received training but not extinction.

For PFC, the multivariate ANOVA showed a significant Drug $\times$ Training interaction for IL $\left(F_{(5,34)}=3.756, P<0.05\right)$ but not for PL $\left(F_{(5,34)}=1.094, P>0.05\right)$ subregions of the mPFC. However, the main effect of training $\left(F_{(5,34)}=42.777, P<0.01\right)$ but not drug $\left(F_{(5,34)}=1.782, P>0.05\right)$ was significant for PL. Tukey post hoc tests revealed that the number of IL $c$-fos IR cells in the Sal/Extinction but not Nic/Extinction group was significantly different from the homecage controls (Ps $<0.05)$. Similarly, Nic/NoExtinction, and Sal/NoExtinction group $c$-fos IR cell numbers were also significantly different from the homecage controls in IL $(P \mathrm{~s}<0.05)$. However, Nic/Extinction group $c$-fos IR cell numbers were not significantly different from the homecage controls $(P s>0.05)$ and the difference between $\mathrm{Nic} /$ Extinction and Sal/Extinction groups approached significance in IL $(P=0.055)$. Still, the number of PL $c$-fos IR cells in the Nic/Extinction, Sal/Extinction, Nic/NoExtinction, and Sal/NoExtinction groups was significantly different than the homecage controls ( $P s<0.05)$. For PL, the Nic/Extinction group did not differ from any other group that received contextual fear conditioning regardless of the extinction condition ( $P \mathrm{~s}>$ 0.05). These results demonstrate that like the hippocampus, the subregions of $\mathrm{mPFC}$ are differentially involved in the effects of acute nicotine on SR of contextual fear. Specifically, IL and PL $c$-fos expression was increased during both SR and memory recall compared with homecage controls but IL activity was somewhat diminished in the Nic/Extinction group only during SR, which may contribute to the enhanced SR shown in this group (Fig. 5B).

Finally, for BLA, a two-way ANOVA yielded a significant interaction between Drug and Training $\left(F_{(5,34)}=8.047, p<0.05\right)$. Moreover, Tukey post hoc analysis showed that the number of $c$-fos IR cells in the Nic/Extinction group was significantly increased compared with the other three groups $(P<0.05)$. In addition, the Nic/NoExtinction group $c$-fos IR cell numbers were significantly different from the homecage controls $(P<0.05)$ but not from the Sal/NoExtinction or Nic/Extinction groups $(P>0.05)$. These results suggest that nicotine-related increases in BLA c-fos activity may potentially contribute to the enhanced SR of contextual fear, similar to vHipp (Fig. 5C). However, acute nicotine does not modulate BLA $c$-fos activity during recall of contextual fear memories in the absence of extinction. Overall, these results show that brain regions involved in the fear extinction are significantly modulated by acute nicotine during SR of contextual fear.

\section{Discussion}

Our results showed that acute nicotine administration $(0.18 \mathrm{~m} /$ $\mathrm{kg}$ ) prior to retesting following a 7-d delay enhanced SR of extinguished contextual fear memories. The effects of acute nicotine were specific to SR as retrieval of contextual fear memories in general was not altered. As shown by our immunohistochemistry experiments, acute nicotine-induced changes in SR were associated with altered $c$-fos immediate early gene expression in brain regions linked to fear extinction. Specifically, our results showed that 
A

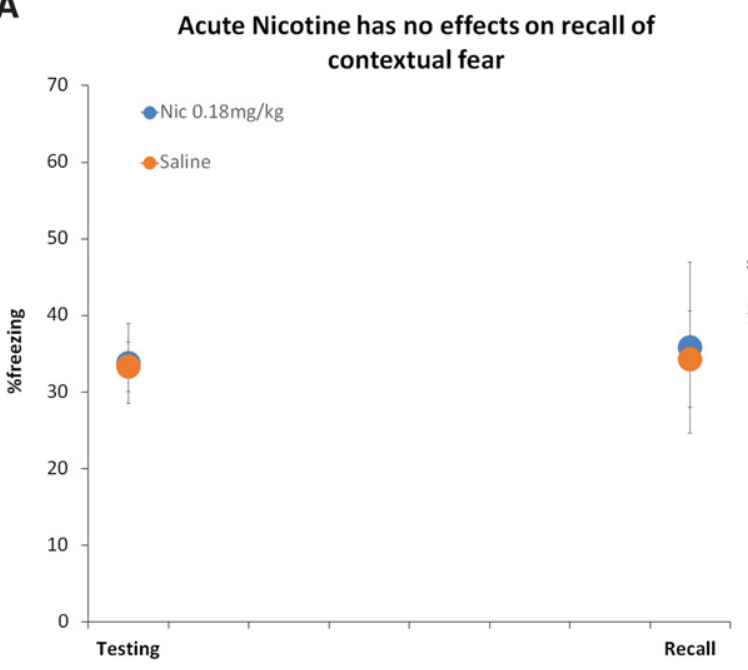

B Acute Nicotine has no effects on recall of contextual

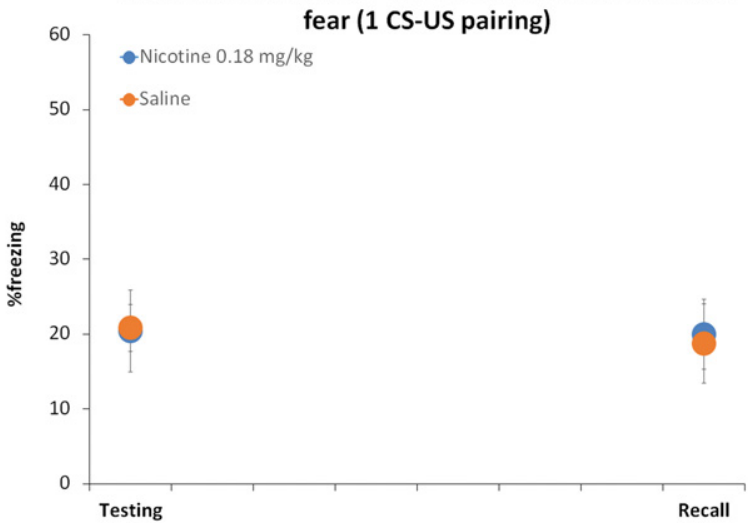

Memory Recall

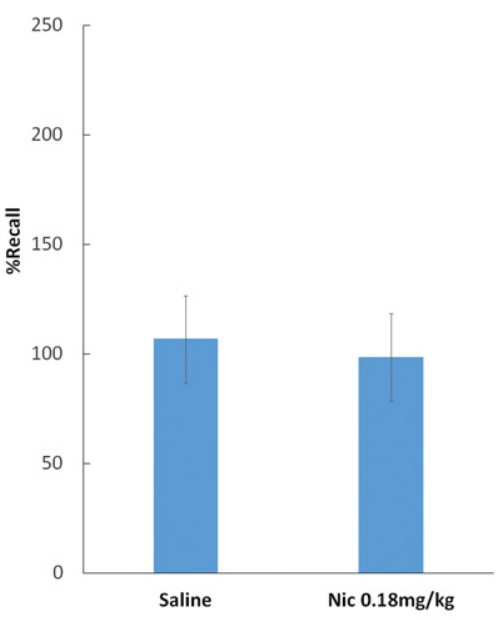

Memory Recall

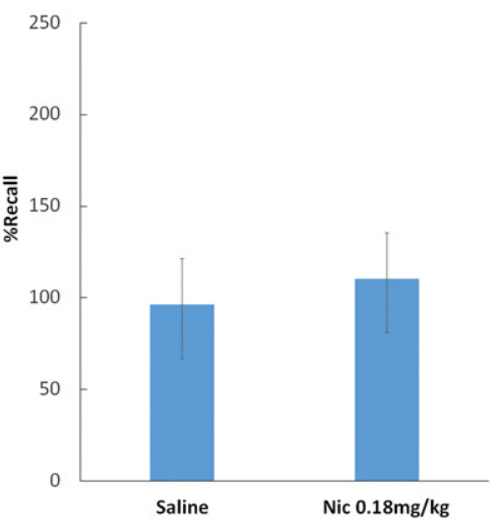

Figure 3. (A) Acute nicotine does not affect retrieval of unextinguished contextual fear memories. (Left panel) Acute-nicotine $(0.18 \mathrm{mg} / \mathrm{kg})$ administration prior to retesting had no effect on retrieval of contextual fear following a 12-d delay; data expressed as \%freezing in mice ( $n=7-8$ per group). (Right panel) Recall of contextual fear represented as \%Recall (average freezing during retesting $\times 100$ /average freezing during initial testing) in the nicotine and saline groups. (B) Acute nicotine does not affect recall of unextinguished contextual fear memories following 1 CS-US pairing. (Left panel) Acute-nicotine $(0.18 \mathrm{mg} / \mathrm{kg})$ administration prior to retesting had no effect on recall of reduced contextual fear following a 12-d delay; data expressed as \%freezing in mice ( $n=8$ per group). (Right panel) Recall of reduced contextual fear represented as \%Recall (average freezing during retesting $\times 100 /$ average freezing during initial testing) in the nicotine and saline groups. Error bars indicate standard error of the mean (SEM).

while $c$-fos expression in vHipp and BLA was increased, IL activation was decreased during SR in the nicotine-treated mice compared with saline-treated mice tested for SR. This suggests that nicotine alone does not modulate activity of these brain regions but does modulate the fear extinction circuitry during SR. We also found that dHipp and PL activity was not altered by SR-nicotine interaction. Moreover, our results showed that acute nicotine did not change $c$-fos expression in any of the examined brain regions following memory recall in the absence of extinction. Thus, acute nicotine may differentially affect recall of extinguished and nonextinguished fear memories.

Overall, from the results of our c-fos immunohistochemistry experiments, a model can be proposed for how acute nicotine alters fear expression during SR (Fig. 6). Following Quirk and Mueller (2008), our model suggests that in the absence of any pharmacological intervention, the direct connections between vHipp and BLA are involved in the encoding and retrieval of contextual fear conditioning (Fig. 6A; Rudy and Matus-Amat 2005). In addition, vHipp provides IL contextual information during extinction retrieval (Fig. 6A). In support of the vHipp's role in con- textual modulation, pharmacological inactivation of vHipp disrupts context-specific retrieval of fear memories (Hobin et al. 2006). Potentially as a response to the contextual information transmitted via vHipp, IL suppresses both BLA activity and BLA output to central nucleus of the amygdala (CeA) (Rosenkranz and Grace 2002; Quirk et al. 2003), which results in reduced fear expression and successful retrieval of contextual extinction memories (Fig. 6A). In line with this model, numerous studies have identified IL, BLA, and the inhibitory projections between these two regions as necessary for extinction retrieval. For example, activity in the BLA subregion of the amygdala has been associated with recovery of fear (Falls et al. 1992; Sierra-Mercado et al. 2011). Furthermore, inhibitory mechanisms within the amygdala may play a crucial role during retrieval of extinction memories (Likhtik et al. 2008). Specifically, several studies showed that prefrontal efferent activation of GABAergic neurons between BLA and CeA, known as intercalated cells (ITC), as well as inhibitory interneurons within BLA reduces conditioned fear response by silencing the CeA (Rosenkranz and Grace 2002; Likhtik et al. 2008). In support, ITC cells receive strong projections from 


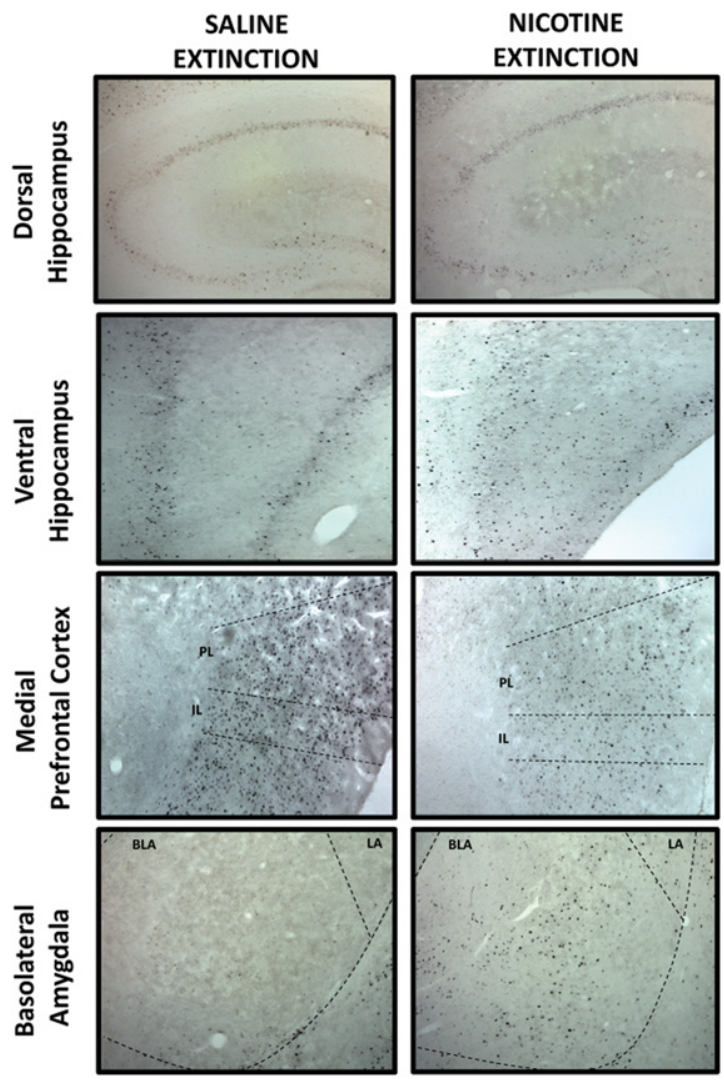

Figure 4. Representative images $(10 \times$ magnification for all images) of the coronal brain sections from the Nic/Extinction and Sal/Extinction group animals showing dHipp, vHipp, mPFC including both PL and IL, and BLA.

the cortical regions such as IL (McDonald et al. 1996; but see Strobel et al. 2015). Increased activity in IL during extinction results in potentiation of ITC cell activation and subsequently decreased activity in the amygdala and reduced fear response (Maren and Quirk 2004; Paré et al. 2004; Baratta et al. 2007). Therefore, while increased BLA function may potentiate SR, IL activation can suppress BLA activity and consequently reduce SR of contextual fear.

It appears that IL activation is necessary for successful retrieval of fear extinction memories (Quirk et al. 2000; Milad and Quirk 2002; Laurent and Westbrook 2009; Cruz et al. 2014). For example, Quirk et al. (2000) showed that lesioning IL prior to training significantly enhanced SR of cued fear after extinction, suggesting a role for IL in consolidation of extinction memories. Moreover, Laurent and Westbrook (2009) found that pharmacological inhibition of IL during retesting enhanced SR of extinguished contextual fear memories whereas inactivation of PL did not affect acquisition and retrieval of extinction memories. Finally, there is evidence showing that excitability of IL neurons increases during extinction and this effect is reversed during SR of cued fear (Cruz et al. 2014). Interestingly, Do-Monte et al. (2015) found no effect of silencing IL on SR of cued fear conditioning using optogenetics, which may suggest that SR of contextual and cued fear are modulated by different prefrontal systems or that methodological differences contribute to the outcome. Overall, these studies show that while vHipp provides both IL and BLA with the necessary contextual information for fear expression, the interplay between IL and BLA determines fear expression during extinction retrieval.
According to our model, after acute nicotine administration, activation of vHipp and BLA increases whereas IL activation diminishes. This results in an enhanced representation of the context as well as reduced IL inhibitory control of BLA activity and output to CeA and, consequently, enhanced expression of contextual fear and enhanced SR (Fig. 6B). It is important to note that vHipp and BLA c-fos expression levels were similar between the Sal/Extinction and homecage control groups whereas the Sal/Extinction group showed significantly higher levels of $c$-fos expression in both PL and IL. In sum, our model suggests that acute nicotine enhances activity in the brain regions associated with fear expression, such as vHipp, BLA, and PL, whereas activity of IL, which is thought to be responsible for the retrieval of extinction memories, is diminished by acute nicotine. Therefore, in line with previous models of fear extinction (Maren and Quirk 2004; Paré et al. 2004), acute nicotine-induced reduction in the cortical control over BLA might be key for the enhanced SR observed in the acute nicotine treated mice.

Although we showed no involvement of dHipp in the effects of acute nicotine on contextual fear recovery, this region has been repeatedly shown to mediate the effects of acute nicotine on acquisition of contextual fear (Kenney et al. 2012). For example, Kenney et al. (2012) found that while direct nicotine infusions into dHipp enhanced acquisition of contextual fear conditioning, vHipp infusions resulted in deficits. However, our results showing asymmetrical involvement of vHipp compared with dHipp during SR and memory recall are consistent with results from previous studies suggesting that retrieval of contextual fear memories is mediated by vHipp whereas dHipp mainly controls encoding of contextual fear conditioning (Hunsaker and Kesner 2008). Thus, dorsal and ventral subregions of the hippocampus mediate different aspects of learned fear versus extinction and have different sensitivity to the effects of nicotine on these behaviors. Therefore, our results showing that vHipp was involved in the effects of acute nicotine on SR of contextual fear but not dHipp suggest that vHipp may assume greater behavioral control than dHipp during SR when nicotine is administered. In addition to dHipp, we did not find any alteration of PL $c$-fos expression between drug conditions whereas it was increased in mice that received contextual fear conditioning. This result is in line with previous studies showing that PL is involved in fear expression but not extinction learning or extinction retrieval (Laurent and Westbrook 2009; Sierra-Mercado et al. 2011). We also found that c-fos expression in IL was increased due to retrieval of contextual fear memories compared with homecage controls. Although multiple studies have shown that IL is required for the retrieval of extinction memories (Quirk et al. 2000; Milad and Quirk 2002; Laurent and Westbrook 2009; Cruz et al. 2014), in line with our results, there is also evidence showing that temporary inactivation of IL prior to testing impaired recall of contextual fear conditioning in the absence of extinction (Resstel et al. 2006, 2008). Therefore, increased $c$-fos expression found in IL may be a result of recall of contextual fear memories in the NoExtinction groups.

Our results indicate a circuitry that may be responsible for the enhancing effects of acute nicotine on SR. However, it is important to acknowledge potential limitations for the interpretation of the data presented here. For example, the c-fos immunohistochemistry method we employed here is not able to differentiate between different types of neurons such as inhibitory GABAergic and excitatory glutamatergic neurons in different brain regions. Therefore, although the increased $c$-fos expression found in the ventral hippocampus in the Nic/Extinction group may mean increased excitatory activity in this brain region, it is possible that our results may indicate reduced activity in the ventral hippocampus if the majority of the $c$-fos expression was 
A

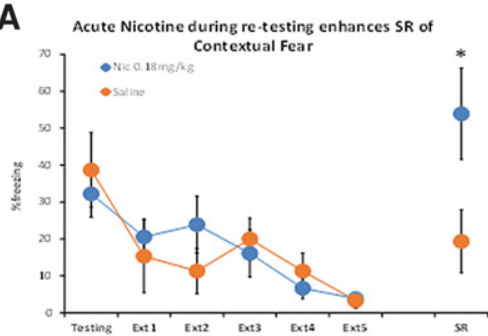

Spontane ous Recovery

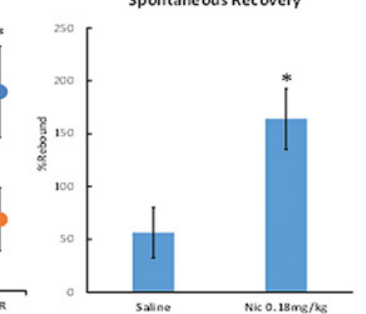

B Acute Nicotine has no effect on recall of contextual

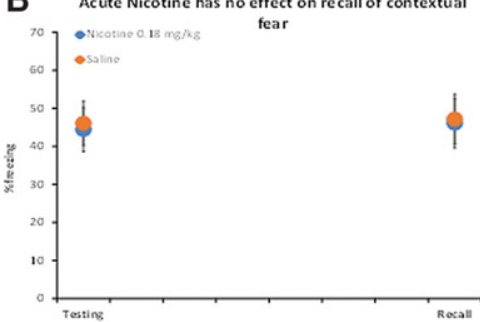

Memory Recall

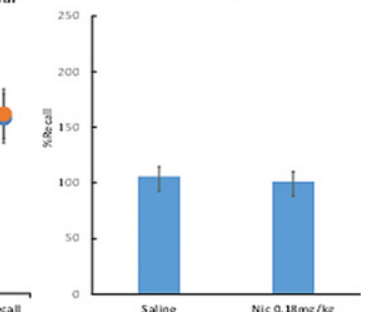

C

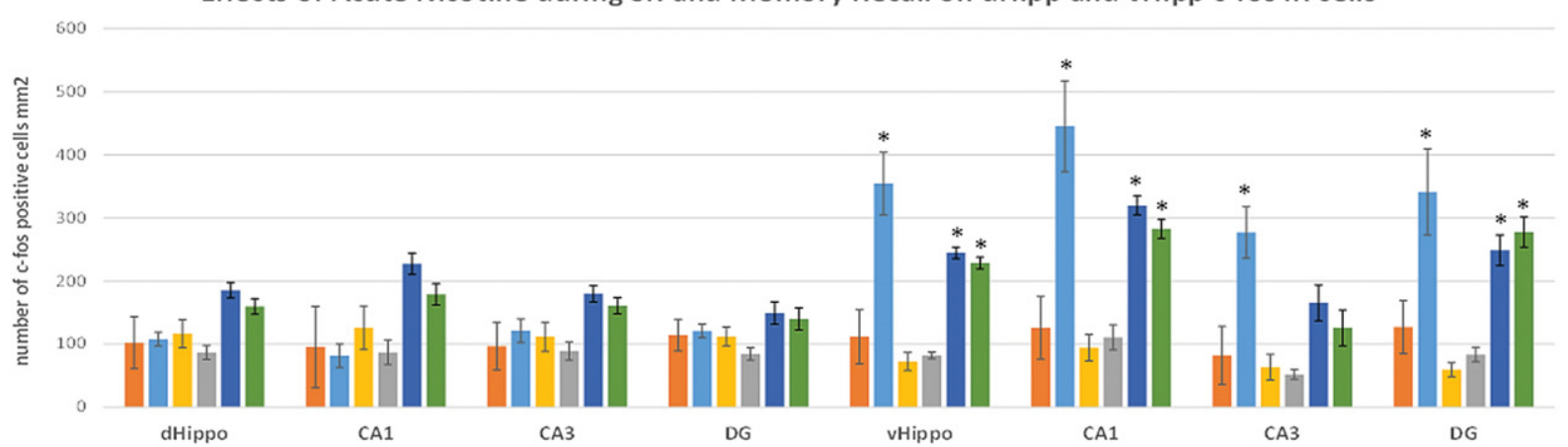

Gal-Extinction $=$ Nic-Extinction $=$ Sal-Homecage $\square$ Nic-Homecage $\square$ Sal-No Extinction $\square$ Nic-No Extinction

D

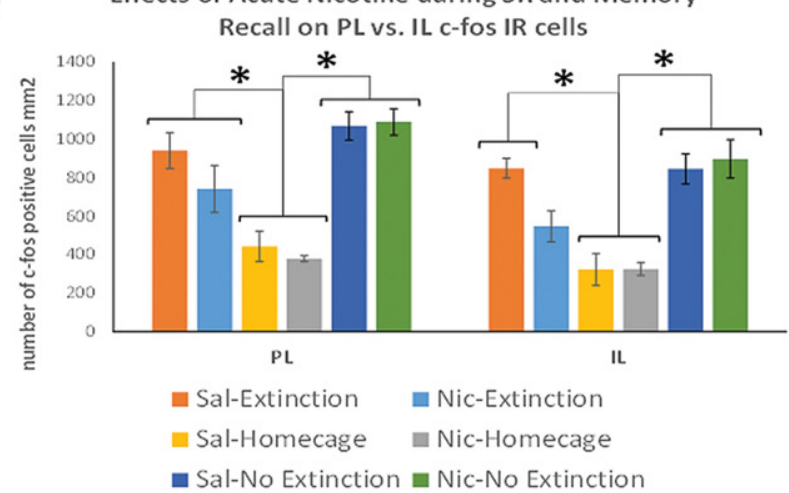

E Effects of Acute Nicotine during SR and Memory Recall on BLA c-fos IR cells

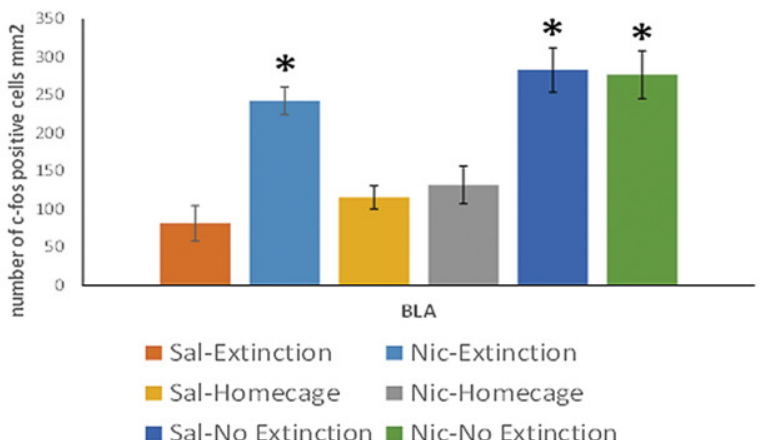

Figure 5. Acute nicotine $(0.18 \mathrm{mg} / \mathrm{kg}$ ) administration prior to testing for SR enhanced $c$-fos expression in vHipp and BLA and decreased it in IL ( $n=6$ per group). (A) Acute nicotine enhances SR of contextual fear. Behavioral data for c-fos experiment. (Left panel) Acute-nicotine $(0.18 \mathrm{mg} / \mathrm{kg})$ administration prior to retesting enhanced SR of contextual fear represented as \%freezing in mice ( $n=5-6$ per group). (Right panel) Spontaneous recovery of contextual fear represented as \%Rebound. (B) Acute nicotine does not affect recall of contextual fear. Behavioral data for $c$-fos experiment. (Left panel) Acute-nicotine $(0.18 \mathrm{mg} / \mathrm{kg})$ administration prior to retesting did not affect recall of contextual fear represented as \%freezing in mice $(n=6$ per group). (Right panel) Recall of contextual fear represented as \%Recall. (C) The number of vHipp c-fos IR cells (averaged across CA1, CA3, and DG subregions) as well as c-fos IR cell numbers in three subregions in the Nic/Extinction group was significantly higher in the Nic/Extinction group in comparison to the Sal/Extinction, Nic/Homecage, and Sal/Homecage groups. No effects were detected for dHipp or any of its subregions. Asterisks represent differences from the Sal/Homecage group at the $P<0.05$ level. $(D)$ IL showed significantly higher $c$-fos expression in the Sal/Extinction, Nic/ NoExtinction, and Sal/NoExtinction, but not in the Nic/Extinction group, compared with homecage controls. The number of $c$-fos IR cells was also reduced in the Nic/Extinction group compared with the Sal/Extinction group $(P=0.55)$. The number of $c$-fos IR cells in PL did not differ between training groups but it was enhanced in these groups compared with homecage control groups. Asterisks represent significant differences between training conditions at the $P<0.05$ level. (E) The number of $c$-fos IR cells BLA was significantly higher in the Nic/Extinction, Nic/NoExtinction, and Sal/NoExtinction groups, but not in the Sal/Extinction group, compared with homecage controls. Error bars indicate standard error of the mean (SEM). For the behavioral experiments, asterisks represent differences from the Saline group at the $P<0.05$ level. Asterisks represent differences from the Sal/Homecage group at the $P<0.05$ level.

elicited from inhibitory neurons. Thus, further analysis of the specific neuron types involved in the effects of acute nicotine on SR of contextual fear is needed to rule out this possibility. Moreover, the model proposed here is based on correlative data of $c$-fos immunoreactivity and assumes discrete roles for different brain regions. Due to these limitations, more direct approaches are needed to elucidate potential causal relationships between the differential activation patterns observed in the present study and specific roles these brain regions may play in SR of contextual fear. In addition, several theoretical explanations may be provided for these results. For example, it is possible that acute nicotine alters inhibitory processes required for successful extinction 
A

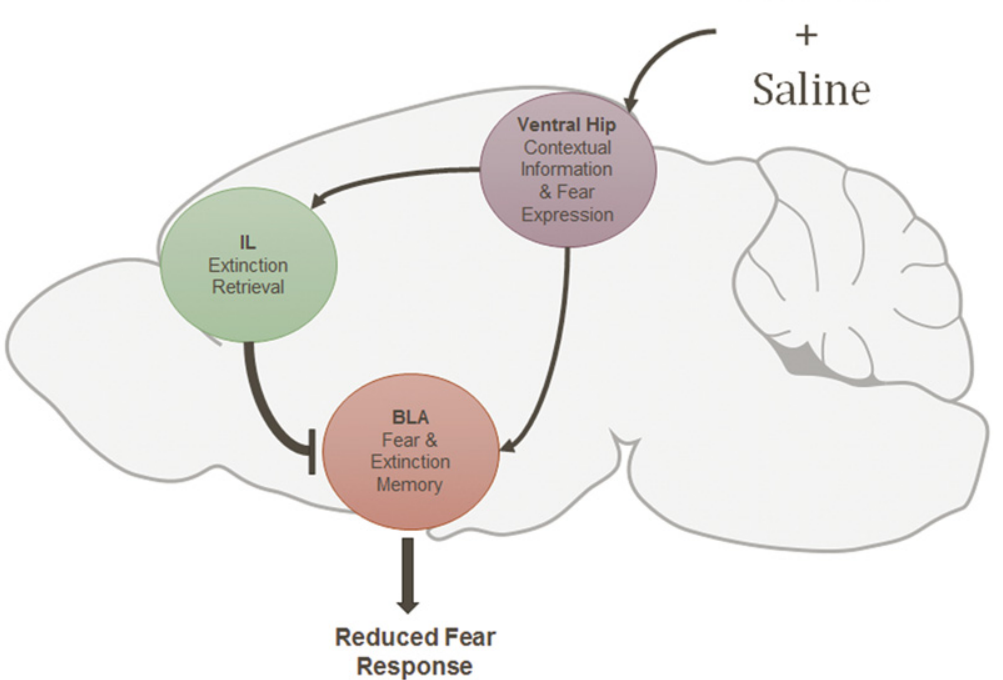

Context

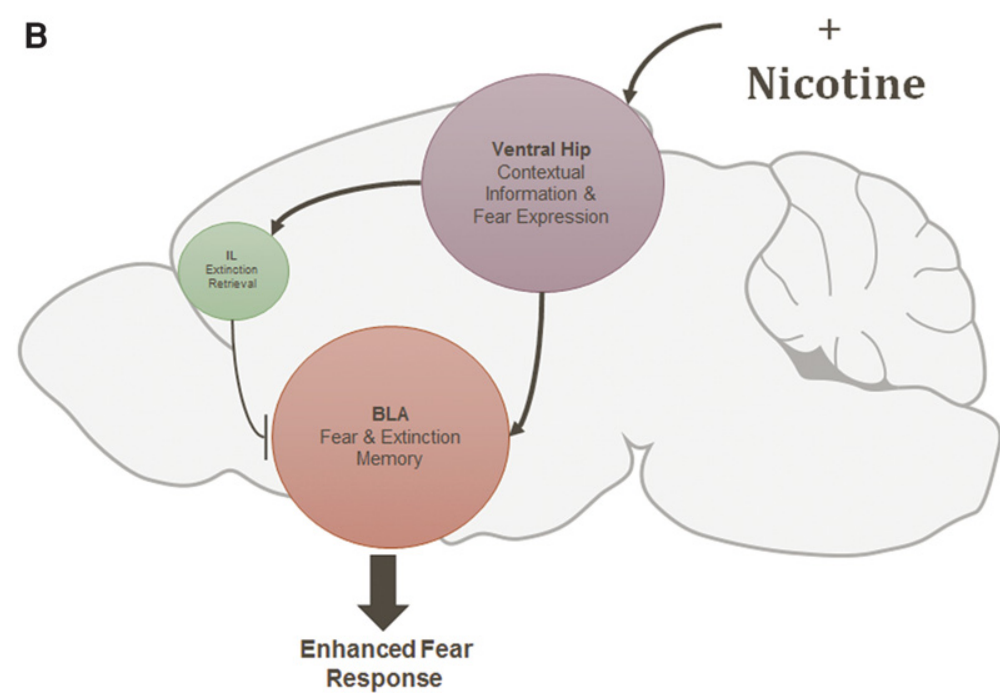

Figure 6. A model for the effects of nicotine on the contextual fear extinction circuitry during SR of contextual fear. $(A)$ Neural circuitry responsible for contextual fear extinction in the absence of nicotine. vHipp projects contextual information to both BLA and IL and, therefore, indirectly controls contextual fear expression and extinction retrieval. BLA plays a central role in forming contextual fear and extinction associations and expressing fear. IL, by inhibiting BLA activity and BLA output to CeA, is a critical site for regulation of extinction memories. (B) Acute nicotine's effects on the contextual fear extinction circuitry. Acute nicotine enhances activity in the vHipp and BLA and reduces activity in IL. Consequently, IL's inhibitory control over BLA is diminished and SR of contextual fear is enhanced. Mouse brain figure: "Mouse brain sagittal" by Jonas Töle-Own work. Licensed under CCO via Wikimedia Commons.

memory recall (Kutlu and Schmajuk 2012) while not affecting recall of excitatory fear memories. It is also possible that acute nicotine administration prior to retesting results in a state-dependent effect, where nicotine creates novel drug-context (Bouton 2002) and, consequently, leads to renewal of contextual fear outside the extinction contexts. Nevertheless, the studies have provided the necessary bases for future examination of these phenomena to identify underlying behavioral mechanisms of acute nicotine's effects.

Although our subjects were C57BL6/J mice, which do not exhibit any PTSD-like phenotype, the present findings can be placed in a greater context of understanding the effects of nicotine on ex-

tinction and how this relates to PTSD. Together with our previous results showing that acute nicotine impairs extinction of contextual fear (Kutlu and Gould 2014) and contextual safety discrimination (Kutlu et al. 2014), results of the present study demonstrate that nicotine is a strong modulator of encoding and retrieval of contextual fear extinction memories. Together with the results showing that PTSD patients have higher rates of smoking initiation (Breslau et al. 2003), this suggests that fear-related symptoms of PTSD such as reexperiencing and avoidance may also be negatively affected by the initial nicotine intake. In agreement with our results, human studies also showed that PTSD symptoms are altered by nicotine dependence. For example, several studies have shown that severity of nicotine dependence was correlated with total PTSD symptoms (Thorndike et al. 2006). There is also evidence showing that PTSD patients show altered contextual information processing during extinction (Rougemont-Bücking et al. 2011). Specifically, Rougemont-Bücking et al. (2011) showed that PTSD patients had reduced activation in the ventromedial PFC compared with healthy individuals when a specific context signaled safety during late extinction and extinction retrieval testing. Moreover, Calhoun et al. (2011) found that the fear response to a trauma-related context was exaggerated in PTSD patients after acute nicotine intake. Together with these results, our results suggest that the period of smoking initiation following trauma may be a critical time for the development and maintenance of PTSD as acute nicotine intake disrupts contextual fear extinction and enhances SR of contextual fear.

\section{Conclusion}

In this present study, we showed that acute nicotine enhances SR of contextual fear but not retrieval of unextinguished contextual fear memories, and this effect is associated with altered $c$-fos expression in vHipp, BLA, and IL regions of fear extinction circuitry. These results clearly suggest that nicotine may have a negative effect on the exposure therapy process in PTSD patients by increasing fear relapse in these individuals and potentially prolonging the course of the disorder. Nevertheless, future translational studies are needed to establish the role of nicotine dependence in fear extinction and SR in clinical and nonclinical populations.

\section{Competing interest statement}

We declare no potential conflict of interest. 


\section{Acknowledgments}

We thank David Braak and Brittany Wicks for their assistance with the immunohistochemistry experiments. T.J.G. was funded with grant support from the National Institute on Drug Abuse (T.J.G., DA017949).

\section{References}

Baratta MV, Christianson JP, Gomez DM, Zarza CM, Amat J, Masini CV, Watkins LR, Maier SF. 2007. Controllable versus uncontrollable stressors bi-directionally modulate conditioned but not innate fear. Neuroscience 146: 1495-1503.

Blanchard DC, Blanchard RJ. 1972. Innate and conditioned reactions to threat in rats with amygdaloid lesions. J Comp Physiol Psychol 81: $281-290$.

Bouton ME. 1988. Context and ambiguity in the extinction of emotional learning: implications for exposure therapy. Behav Res Ther 26: $137-149$.

Bouton ME. 2002. Context, ambiguity, and unlearning: sources of relapse after behavioral extinction. Biol Psychiatry 52: 976-986.

Breslau N, Kessler RC, Chilcoat HD, Schultz LR, Davis GC, Andreski P. 1998. Trauma and posttraumatic stress disorder in the community: the 1996 Detroit Area Survey of Trauma. Arch Gen Psychiatry 55: $626-632$.

Breslau N, Davis GC, Schultz LR. 2003. Posttraumatic stress disorder and the incidence of nicotine, alcohol, and other drug disorders in persons who have experienced trauma. Arch Gen Psychiatry 60: 289-294.

Breslau N, Novak SP, Kessler RC. 2004. Psychiatric disorders and stages of smoking. Biol Psychiatry 55: 69-76.

Calhoun PS, Wagner HR, McClernon FJ, Lee S, Dennis MF, Vrana SR, Clancy CP, Collie CF, Johnson YC, Beckham JC. 2011. The effect of nicotine and trauma context on acoustic startle in smokers with and without posttraumatic stress disorder. Psychopharmacology (Berl) 215: 379-389.

Chambless DL, Ollendick TH. 2001. Empirically supported psychological interventions: controversies and evidence. Annu Rev Psychol 52: $685-716$.

Corcoran KA, Desmond TJ, Frey KA, Maren S. 2005. Hippocampal inactivation disrupts the acquisition and contextual encoding of fear extinction. J Neurosci 25: 8978-8987.

Craske MG, Rachman SJ. 1987. Return of fear: perceived skill and heart-rate responsivity. Br J Clin Psychol 26: 187-199.

Cruz E, López AV, Porter JT. 2014. Spontaneous recovery of fear reverses extinction-induced excitability of infralimbic neurons. PLoS One 9: e103596.

Davis JA, James JR, Siegel SJ, Gould TJ. 2005. Withdrawal from chronic nicotine administration impairs contextual fear conditioning in C57BL/6 mice. J Neurosci 25: 8708-8713.

Davis JA, Porter J, Gould TJ. 2006. Nicotine enhances both foreground and background contextual fear conditioning. Neurosci Lett 394: $202-205$.

Do-Monte FH, Manzano-Nieves G, Quiñones-Laracuente K, Ramos-Medina L, Quirk GJ. 2015. Revisiting the role of infralimbic cortex in fear extinction with optogenetics. J Neurosci 35: 3607-3615.

Falls WA, Miserendino MJ, Davis M. 1992. Extinction of fear-potentiated startle: blockade by infusion of an NMDA antagonist into the amygdala. J Neurosci 12: 854-863.

Gould TJ, Higgins JS. 2003. Nicotine enhances contextual fear conditioning in C57BL/6J mice at 1 and 7 days post-training. Neurobiol Learn Mem 80: 147-157.

Gould TJ, Lommock JA. 2003. Nicotine enhances contextual fear conditioning and ameliorates ethanol-induced deficits in contextual fear conditioning. Behav Neurosci 117: 1276.

Greenberg JB, Ameringer KJ, Trujillo MA, Sun P, Sussman S, Brightman M, Pitts SR, Leventhal AM. 2012. Associations between posttraumatic stress disorder symptom clusters and cigarette smoking. Psychol Addict Behav 26: 89-98.

Gualtieri CT, Morgan DW. 2008. The frequency of cognitive impairment in patients with anxiety, depression, and bipolar disorder: an unaccounted source of variance in clinical trials. J Clin Psychiatry 69: $1122-1130$

Hawkins KA, Cougle JR. 2013. The effects of nicotine on intrusive memories in nonsmokers. Exp Clin Psychopharmacol 21: 434-442.

Hobin JA, Ji J, Maren S. 2006. Ventral hippocampal muscimol disrupts context-specific fear memory retrieval after extinction in rats. Hippocampus 16: 174-182.

Hunsaker MR, Kesner RP. 2008. Dissociations across the dorsal-ventral axis of CA3 and CA1 for encoding and retrieval of contextual and auditory-cued fear. Neurobiol Learn Mem 89: 61-69.
Kenney JW, Raybuck JD, Gould TJ. 2012. Nicotinic receptors in the dorsal and ventral hippocampus differentially modulate contextual fear conditioning. Hippocampus 22: 1681-1690.

Kutlu MG, Gould TJ. 2014. Acute nicotine delays extinction of contextual fear in mice. Behav Brain Res 263: 133-137.

Kutlu MG, Gould TJ. 2015. Nicotine modulation of fear memories and anxiety: implications for learning and anxiety disorders. Biochem Pharmacol 97: 498-511.

Kutlu MG, Schmajuk NA. 2012. Solving Pavlov's puzzle: attentional, associative, and flexible configural mechanisms in classical conditioning. Learn Behav 40: 269-291.

Kutlu MG, Oliver C, Gould TJ. 2014. The effects of acute nicotine on contextual safety discrimination. J Psychopharmacol 28: 1064-1070.

Kutlu MG, Holliday E, Gould TJ. 2016. High-affinity $\alpha 4 \beta 2$ nicotinic receptors mediate the impairing effects of acute nicotine on contextual fear extinction. Neurobiol Learn Mem 128: 17-22.

Laurent V, Westbrook RF. 2009. Inactivation of the infralimbic but not the prelimbic cortex impairs consolidation and retrieval of fear extinction. Learn Mem 16: 520-529.

Likhtik E, Popa D, Apergis-Schoute J, Fidacaro GA, Paré D. 2008. Amygdala intercalated neurons are required for expression of fear extinction. Nature 454: 642-645.

Maren S, Quirk GJ. 2004. Neuronal signalling of fear memory. Nat Rev Neurosci 5: 844-852.

Martinez RC, Gupta N, Lázaro-Muñoz G, Sears RM, Kim S, Moscarello JM, LeDoux JE, Cain CK. 2013. Active vs. reactive threat responding is associated with differential c-Fos expression in specific regions of amygdala and prefrontal cortex. Learn Mem 20: $446-452$.

McDonald AJ, Mascagni F, Guo L. 1996. Projections of the medial and lateral prefrontal cortices to the amygdala: a Phaseolus vulgaris leucoagglutinin study in the rat. Neuroscience 71: 55-75.

Milad MR, Quirk GJ. 2002. Neurons in medial prefrontal cortex signal memory for fear extinction. Nature 420: 70-74.

Morgan MA, Romanski LM, LeDoux JE. 1993. Extinction of emotional learning: contribution of medial prefrontal cortex. Neurosci Lett 163: $109-113$.

Myers KM, Davis M. 2002. Behavioral and neural analysis of extinction. Neuron 36: $567-584$

Norrholm SD, Jovanovic T, Vervliet B, Myers KM, Davis M, Rothbaum BO, Duncan EJ. 2006. Conditioned fear extinction and reinstatement in a human fear-potentiated startle paradigm. Learn Mem 13: 681-685.

Paré D, Quirk GJ, Ledoux JE. 2004. New vistas on amygdala networks in conditioned fear. J Neurophysiol 92: 1-9.

Pavlov IP. 1927. Conditioned reflexes: an investigation of the physiological activity of the cerebral cortex. Ann Neurosci 17: 136-141.

Paxinos G, Franklin K. 2001. The mouse brain atlas in stereotaxic coordinates. Academic, San Diego, CA.

Pomerleau CS, Pomerleau OF. 1987. The effects of a psychological stressor on cigarette smoking and subsequent behavioral and physiological responses. Psychophysiology 24: 278-285.

Quirk GJ, Mueller D. 2008. Neural mechanisms of extinction learning and retrieval. Neuropsychopharmacology 33: 56-72.

Quirk GJ, Russo GK, Barron JL, Lebron K. 2000. The role of ventromedial prefrontal cortex in the recovery of extinguished fear. J Neurosci 20: 6225-6231.

Quirk GJ, Likhtik E, Pelletier JG, Paré D. 2003. Stimulation of medial prefrontal cortex decreases the responsiveness of central amygdala output neurons. J Neurosci 23: 8800-8807.

Resstel LBM, Joca SRL, Guimaraes FG, Correa FMA. 2006. Involvement of medial prefrontal cortex neurons in behavioral and cardiovascular responses to contextual fear conditioning. Neuroscience 143: 377-385.

Resstel LBM, de Aguiar Corrêa FM, Guimarães FS. 2008. The expression of contextual fear conditioning involves activation of an NMDA receptor-nitric oxide pathway in the medial prefrontal cortex. Cereb Cortex 18: 2027-2035.

Rosenkranz JA, Grace AA. 2002. Cellular mechanisms of infralimbic and prelimbic prefrontal cortical inhibition and dopaminergic modulation of basolateral amygdala neurons in vivo. J Neurosci 22: 324-337.

Rothbaum BO, Davis M. 2003. Applying learning principles to the treatment of Post-Trauma reactions. Ann N Y Acad Sci 1008: 112-121.

Rougemont-Bücking A, Linnman C, Zeffiro TA, Zeidan MA, Lebron-Milad K, Rodriguez-Romaguera J, Rauch SL, Pitman RK, Milad MR. 2011. Altered processing of contextual information during fear extinction in PTSD: an fMRI study. CNS Neurosci Ther 17: 227-236.

Rudy JW, Matus-Amat P. 2005. The ventral hippocampus supports a memory representation of context and contextual fear conditioning: implications for a unitary function of the hippocampus. Behav Neurosci 119: $154-163$. 
Santini E, Muller RU, Quirk GJ. 2001. Consolidation of extinction learning involves transfer from NMDA-independent to NMDA-dependent memory. J Neurosci 21: 9009-9017.

Sierra-Mercado D, Padilla-Coreano N, Quirk GJ. 2011. Dissociable roles of prelimbic and infralimbic cortices, ventral hippocampus, and basolateral amygdala in the expression and extinction of conditioned fear. Neuropsychopharmacology 36: 529-538.

Strobel C, Marek R, Gooch HM, Sullivan RK, Sah P. 2015. Prefrontal and auditory input to intercalated neurons of the amygdala. Cell Rep 10: $1435-1442$.

Thorndike FP, Wernicke R, Pearlman MY, Haaga DA. 2006. Nicotine dependence, PTSD symptoms, and depression proneness among male and female smokers. Addict Behav 31: 223-231.

Vervliet B, Craske MG, Hermans D. 2013. Fear extinction and relapse: state of the art. Аппи Rev Clin Psychol 9: 215-248.
Wing VC, Shoaib M. 2008. Contextual stimuli modulate extinction and reinstatement in rodents self-administering intravenous nicotine. Psychopharmacology 200: $357-365$.

Zhao C, Li M. 2010. c-Fos identification of neuroanatomical sites associated with haloperidol and clozapine disruption of maternal behavior in the rat. Neuroscience 166: 1043-1055.

Ziedonis D, Hitsman B, Beckham JC, Zvolensky M, Adler LE, Audrain-McGovern J, Breslau N, Brown RA, George TP, Williams J, et al. 2008. Tobacco use and cessation in psychiatric disorders: National Institute of Mental Health report. Nicotine Tob Res 10: $1691-1715$.

Received April 15, 2016; accepted in revised form May 18, 2016. 


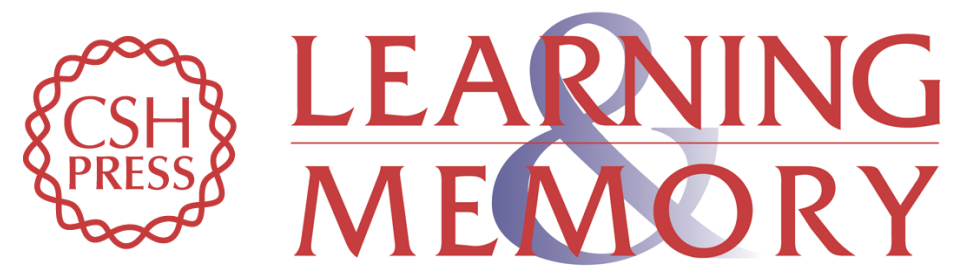

\section{Acute nicotine enhances spontaneous recovery of contextual fear and changes $c$-fos early gene expression in infralimbic cortex, hippocampus, and amygdala}

Munir G. Kutlu, Jessica M. Tumolo, Erica Holliday, et al.

Learn. Mem. 2016, 23:

Access the most recent version at doi:10.1101//m.042655.116

Supplemental http://learnmem.cshlp.org/content/suppl/2016/07/07/23.8.405.DC1
Material

References This article cites 58 articles, 11 of which can be accessed free at: http://learnmem.cshlp.org/content/23/8/405.full.html\#ref-list-1

Creative This article is distributed exclusively by Cold Spring Harbor Laboratory Press for the Commons first 12 months after the full-issue publication date (see

License http://learnmem.cshlp.org/site/misc/terms.xhtml). After 12 months, it is available under a Creative Commons License (Attribution-NonCommercial 4.0 International), as described at http://creativecommons.org/licenses/by-nc/4.0/.

Email Alerting Receive free email alerts when new articles cite this article - sign up in the box at the Service top right corner of the article or click here. 